\title{
Benchmarking Characteristics of Steam Assisted Gravity Drainage (SAGD) Projects: Based On Interview Findings
}

\author{
Elias Ikpe (Corresponding author) \\ Ph.D, Civil Engineering, University of Calgary, Alberta, Canada \\ E-mail: eliasikpe@yahoo.com
}

Jatinder Kumar

MSc. P.Eng., University of Calgary, Alberta, Canada

George Jergeas

Ph.D, P.Eng., Civil Engineering, University of Calgary, Alberta, Canada

Received: June 16, 2015 Accepted: July 18, 2015 Published: August 7, 2015

doi:10.5296/bmh.v3i2.8126 URL: http://dx.doi.org/10.5296/bmh.v3i2.8126

\begin{abstract}
SAGD is a relatively new method of oil extraction and recovery in Alberta oil and gas industry and the number of new SAGD plants in Alberta is expected to increase within this decade. The paper discusses the interviews finding of benchmarking characteristics of the SAGD projects. The research reviewed and analysed definition of capacity, main features, life cycle/ phases of SAGD projects and also major risks associated with it. A qualitative research methodology was employed in investigating the characteristics of SAGD projects. Interviews were conducted with industry practitioners, which contained open-ended questions. The result found the definition of capacity of SAGD projects is barrels/day and from the lifecycle of SAGD projects procurement/cosntruction phase is $75 \%$ of the total project cost while other phase in total constiutues the $25 \%$ of the total cost of the project. On the schedule prospective, procurement/construction phase constitute the $55 \%$ of the total project duration. This method has the potential to contribute to a reduction in cost and schedule overruns and improves SAGD project performance. It is concluded that the results of the study will help in achieving a higher rate of productivity in the Alberta oil and gas industry.
\end{abstract}


Keywords: SAGD projects, capacity, main features, life cycle/ phases and risks 


\section{Introduction}

Benchmarking is regarded as a sequence of activities involving process and assessment (Moriarity \& Smallman, 2009). It was applied in knowledge management initiatives (McAdam \& McCreedy 1999), in total quality management (Franceschini et al., 2006), supply chain management (Deming, 1982), Six Sigma (Xerox, 1979) (as cited in Moriarity \& Smallman, 2009), performance measurement (Anderson \& McAdam, 2004; Alstete, 2008). It is applied in Alberta oil and gas industry to improve project performance. In the Alberta oil and gas industry, the application of benchmarking SAGD projects is important because of the vast reserves of oil. With large part of oil sands production coming from the employment of in situ extraction and SAGD being the most advanced technology currently available, the number of new plants using the technology is likely to increase significantly (Alnoor, 2010).

The paper discusses the interviews finding of characteristics of the SAGD projects, which would be very beneficial to project owners and the EPC contractors in effectively executing and completing their projects on time and within budget especially SAGD projects. The research reviewed and analysed definition of capacity, main features, life cycle/ phases of SAGD projects and also major risks associated with it. The paper found the most common definition of capacity of SAGD projects so that it could be used to produce the related benchmarking metrics. From the main feature, it generalizes a level 2 break down for SAGD projects where more benchmarking metrics can be created based upon the breakdown. The paper also determines how the life cycle of SAGD projects is different from other industrial projects. It concludes that the results of the study will help in achieving a higher rate of productivity in the Alberta oil and gas industry.

\section{Background}

The Canada's Oil sands are mainly found in three areas: the Athabasca, Peace River and Cold Lake. Oil sands are near surface in Fort Mcmurray/Athabasca region while deeper in other areas (Alnoor, 2010). Depending upon the depth of oil sands, the oil sands are recovered mainly by two methods: mining and drilling (In-situ). Mining method is used if the oil sand reserves are shallow (less than $75 \mathrm{~m}$ from surface) while drilling methods is used for deeper reserves. In situ oil extraction is more environmental friendly as compared to mining method (Alnoor, 2010). Jergeas (2008) identified complexity associated with the delivery of construction projects in the Alberta oil and gas sector as due to geographic location, weather condition, size of projects and contractual arrangement. These effects were further compounded by extremes experienced in Alberta related to such things as labour availability.

Figure 1 below shows that Canada has third largest oil reserves in the world after Venezuela and Saudi Arabia, and out of these reserves, 97\% of these reserves are oil sands (CAPP, 2014). Oil sand reserves constitute the $53 \%$ reserves, which are open to private sector. 


\section{Global Crude Oil Reserves by Country}

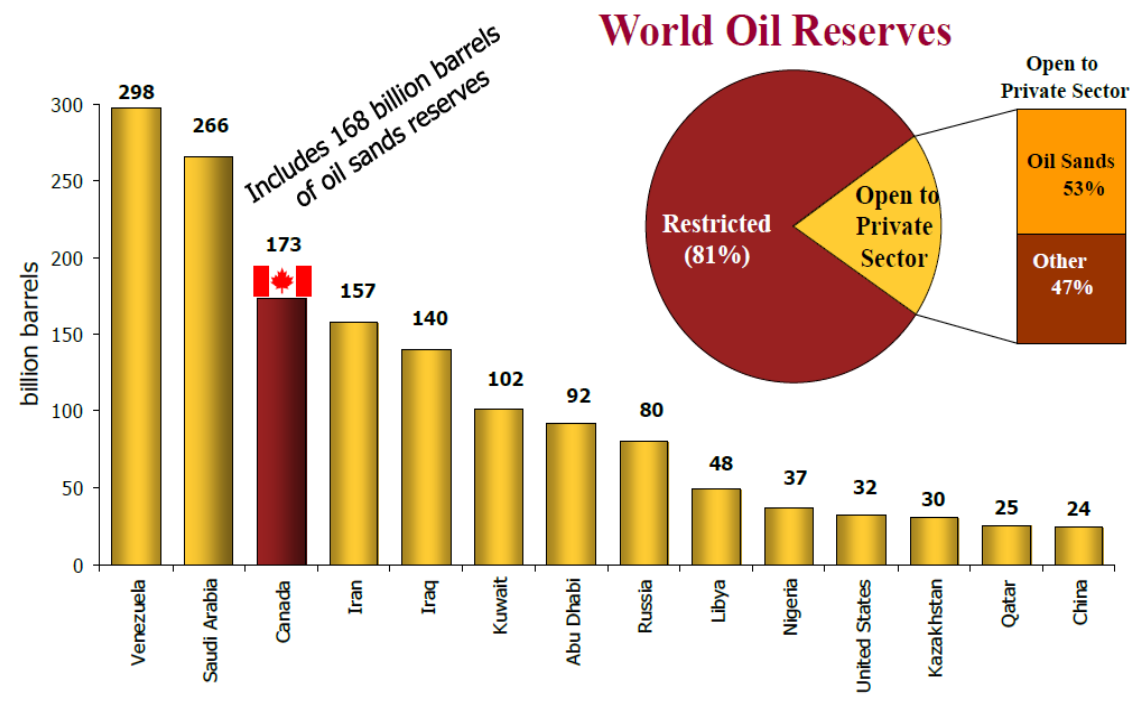

Figure 1. Global crude oil reserves by country

Sources: Alnoor (2010).

The success of Alberta oil and gas industry can be further improved by improving the SAGD project performance. Considering that many recent large oil \& gas projects in Alberta have had significant cost overruns (Jergeas, 2008), a great deal of attention will be focused by project owners, contractors, suppliers, and academia on how to make the project management of SAGD projects more effective. Therefore, there is a need to analyse the project performance improvement for the successful execution of oil \& gas projects with a focus on SAGD projects. A comprehensive benchmarking system can identify areas for work process improvement. The process helps organization to understand their operations better and sets goal for improvement. Any organization that wants to improve its performance should follow this process. The only way to truly and objectively know whether or not project execution is improving is through continuous measurement (Jergeas, 2009).

\section{Research Methodology}

There are three principal research approaches that can be employed namely qualitative, quantitative and mixed methods (Creswell, 2003). The qualitative methodology was employed and is considered to be the most appropriate strategy in the context of this study for collecting data. Lincoln and Guba (1985) described the qualitative research approach as an enquiry process of comprehending a social or human problem phenomenon based on building a complex holistic picture formed with words, reporting detailed views of informants and conducted in a natural setting. Walker (1997) and Creswell (2003) further described qualitative methodology as explanatory in nature with the principal aim of trying to unearth answers to how? and why? questions. The method can be used to better understand and to gain new perspectives on issues about which is already known. The quantitative approach 


\section{Macrothink}

was not adopted because it would not be sufficient in this case with limited number of oil and gas projects in Alberta. For the purpose of this research, the authors consider qualitative methodology as more suitable to explore the metrics to benchmark SAGD projects.

\section{Development of Questionnaire}

The questionnaire was designed primarily to elicit information from participants in Alberta oil and gas industries on SAGD projects. The interviews were conducted from different companies including owner, engineering and contractor companies. The selected companies are involved in the COAA benchmarking program, which support the research activities carried at the University of Calgary. The interviews were conducted with experts in the Alberta oil and gas industry. They are mostly responsible for project performance in their respective organizations and also are knowledgeable on issues concerning COAA performance assessment systems. Interviews were conducted with these personnel from 17 construction and oil and gas industries in Alberta. The interviewees were chosen from owner, engineering, procurement and construction (EPC) companies. Semi-structured interviews were conducted to assess the effectiveness and use of existing system.

\section{Research Findings of the Interview}

General information was collected from the interview participants as shown in figure 2 below. These include: role, locations, experience related to SAGD projects. Name, company and contact information were optional.

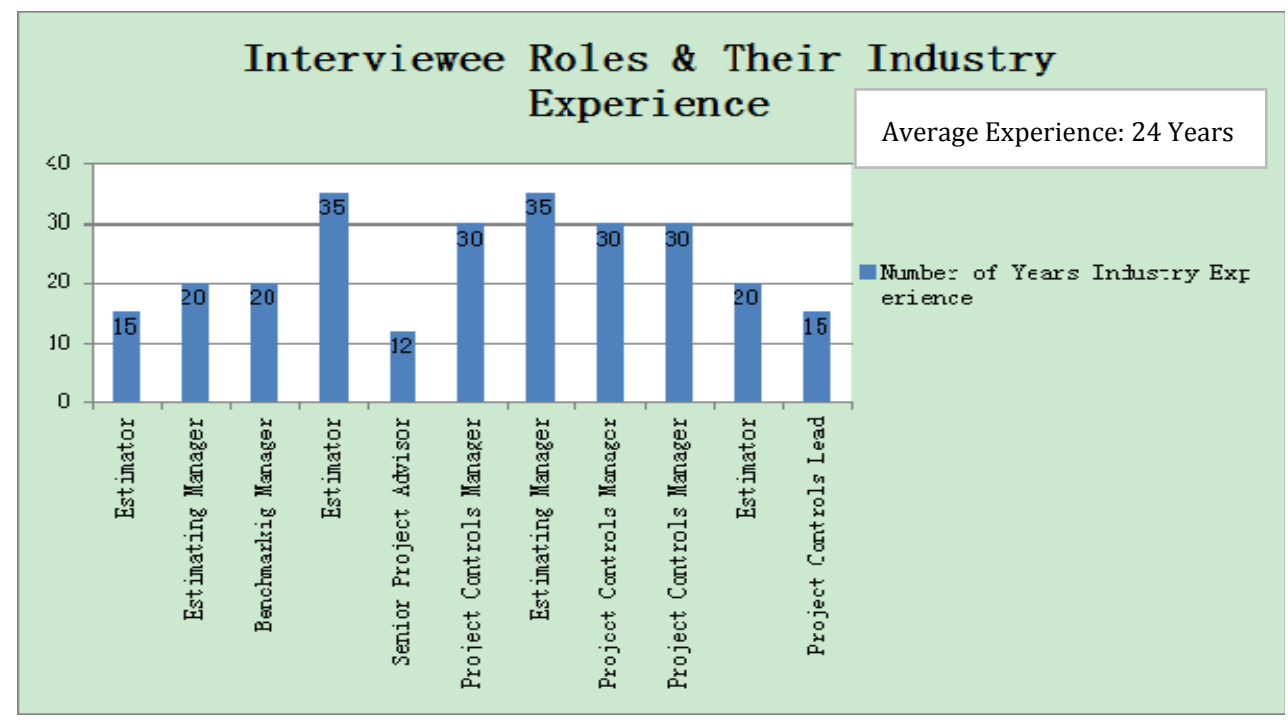

Figure 2. Experience related to SAGD projects

Approximate how many SAGD Projects have your company dealt during the last fifteen years? In response to this question, it was revealed by respondents that most companies have experience of 7 SAGD related projects in the last 15 years as shown in figure 3 below. 


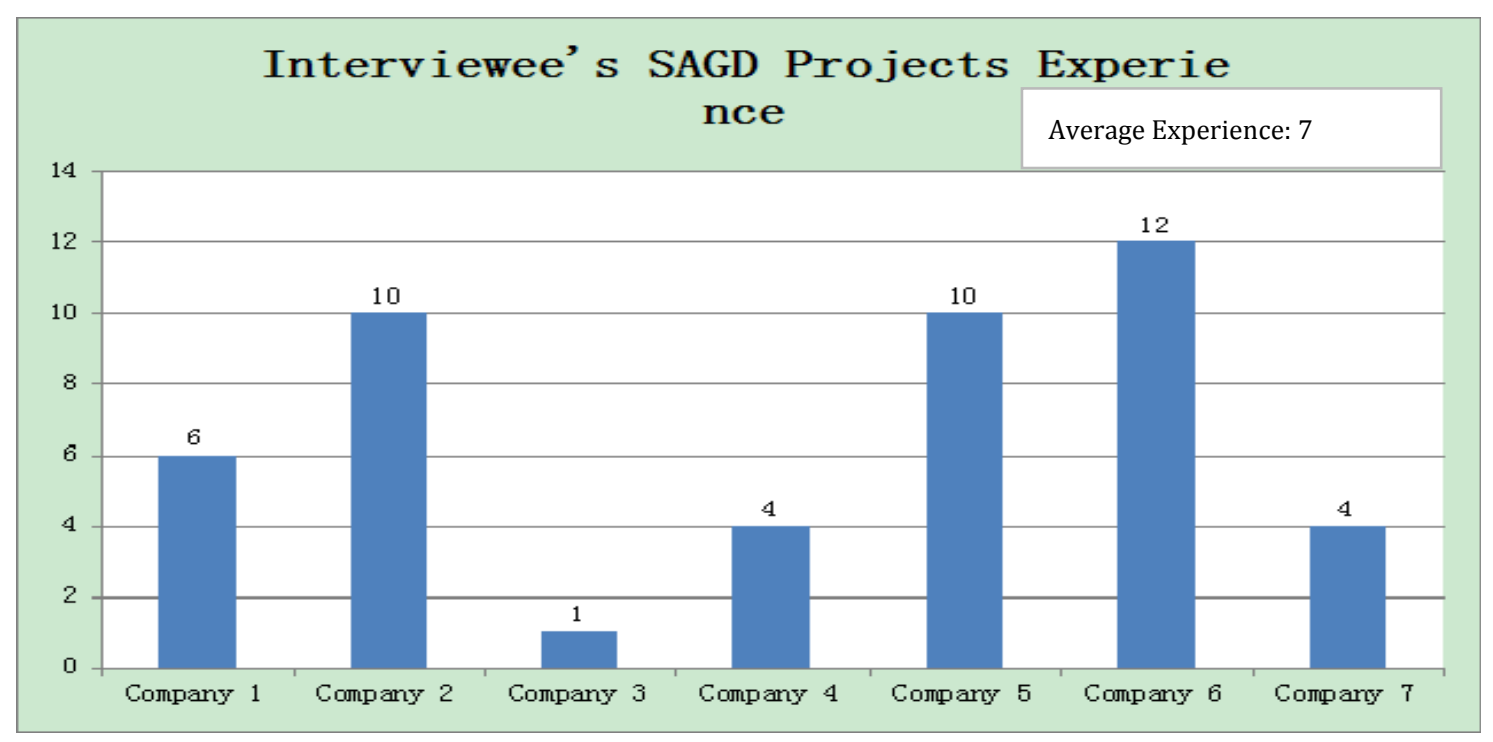

Figure 3. Interviewee’s SAGD projects experience

\subsection{Definition of Capacity}

The interviewers were asked to define the capacity of SAGD projects. In response to this question, most participants felt that the most common definition of capacity of SAGD projects is barrels/day. However, some respondents recommended the followings:

- Dollar Value of Project based upon the capacity.

- $\quad$ Steam Oil ratio

- $\quad$ Cold water equivalent Steam capacity in KPSD

\subsection{Main Features}

The interviewees were asked the work breakdown structure (WBS) of the SAGD projects. As per industry common practice, usually SAGD projects are broken down in level 2 WBS and executed by different subcontractor. For example, Central Processing Facility (CPF) of plant is engineering and constructed by one contractor while different contractors construct Well Pads concurrently. Based on the interviews, the most agreeable work breakdown structure for SAGD projects is:

o Central Processing Plant

o Well Pads/Well Pairs including drilling and completion

o Source and Disposal Water Wells

o Gathering \& Distribution lines including export pipelines. Above ground and underground pipelines

o Utilities include storage, cogen, substation, infrastructure 


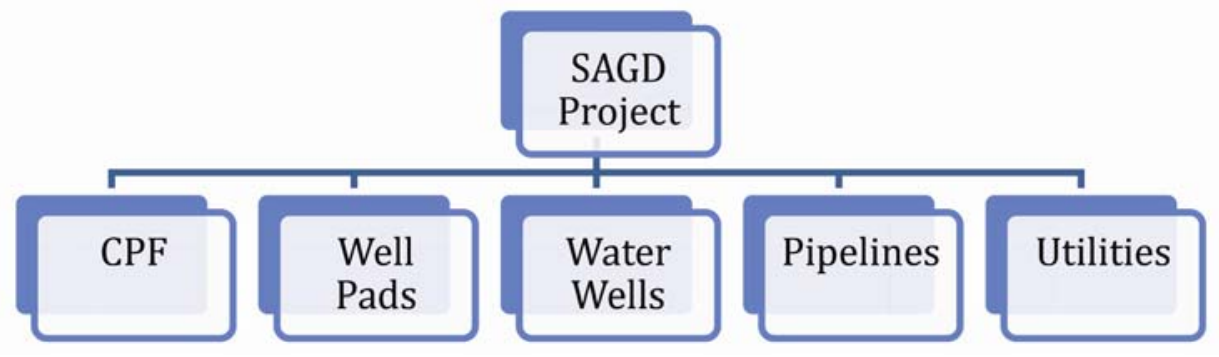

Figure 4. SAGD project

Figure 4 above shows the agreeable work breakdown for SADG projects. During the interviews, it was also found that out of the above breakdown CPF is more expensive when compared to other breakdown structure.

\subsection{Life Cycle/ Phases}

The interviewees were asked about the different phases of the SAGD projects. In response to this question, it was found that different companies are using different terminology to define the various life cycle phases of SAGD projects. The life cycle of SAGD projects is similar to other industrial projects. The interviewees were further asked for cost and schedule breakdown for each phase. Most respondents agreed that percentage varies according to the size and capacity of the project. It is necessary to mention that these numbers are standards but can change depending upon the size and complexity of projects. As per information obtained from the experts, table 1 below further shows the cost and schedule breakdown for life cycle of SAGD projects.

Table 1. Life cycle of SAGD projects

\begin{tabular}{|l|l|l|}
\hline Phase Name & Cost (\%) & Schedule (\%) \\
\hline Feasibility & $3 \%$ & $1 \%$ \\
\hline Design Basis Memorandum (DBM) & $7 \%$ & $2 \%$ \\
\hline Detail Engineering & $12 \%$ & $7 \%$ \\
\hline Procurement, Construction \& Management & $75 \%$ & $78 \%$ \\
\hline Start-up \& Commissioning & $3 \%$ & $12 \%$ \\
\hline
\end{tabular}

Table 1 above and Figure 5 below shows that Procurement/Cosntruction phase is $75 \%$ of the total project cost while other phase in total constiutues the $25 \%$ of the total cost of the project. 


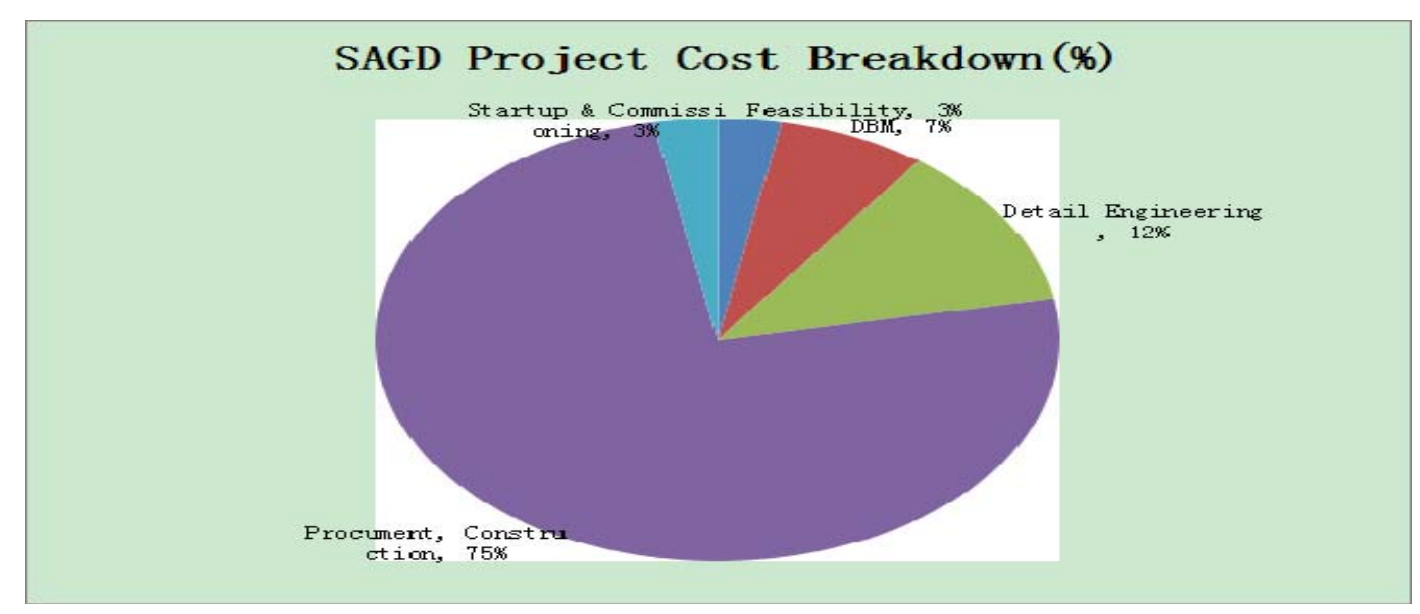

Figure 5. SAGD projects cost breakdown (\%)

On the schedule prospective, figure 6 below shows procurement/construction phase constitute the $55 \%$ of the total project duration. In this breakdown, the procurement and construction duration overlap with each other

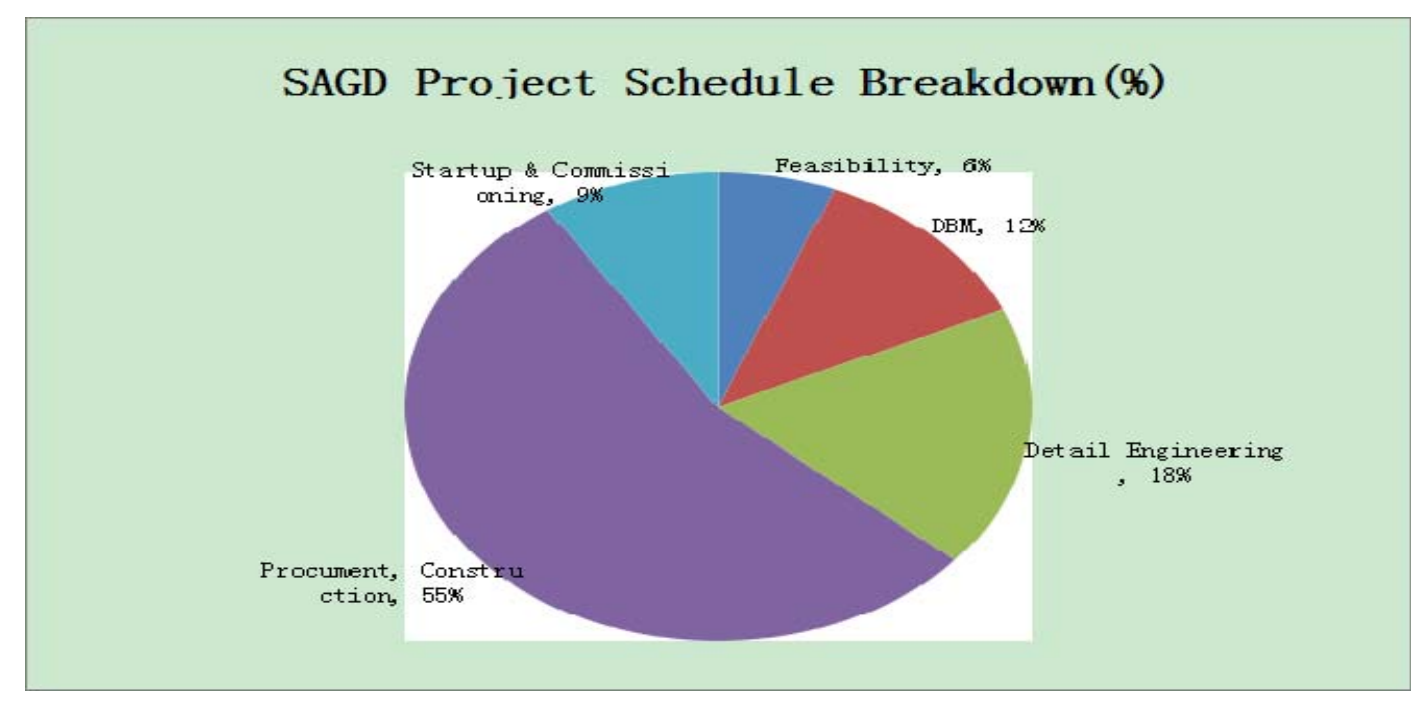

Figure 6. SAGD projects schedule breakdown (\%)

\subsection{Formation of Realistic Estimates/Schedule at Front-End Phases of the Project}

The participants were asked if estimate and schedule developed at the front-end are realistic or not? According to the experts, the quality of estimate/schedule at Front End and Engineering Design (FEED) phase depends upon many factors such as size and complexity of the project. However, all the experts agreed that a day SAGD is a relatively established technology and estimate and schedule developed at the FEED phase end up +_ 15\%. 


\section{Macrothink}

Business and Management Horizons

ISSN 2326-0297

2015, Vol. 3, No. 2

\section{SAGD Metrics}

The paper acknowledges that there do existing COAA performance metrics, which are cost, schedule, change, safety and rework and engineering and construction productivity metrics. The engineering productivity metrics are captured for significant work activities for the following design disciplines: concrete, structural steel, piping, electrical, instrumentation, equipment while construction productivity metrics are captured for the following disciplines: concrete, structural steel, piping, electrical, instrumentation, equipment, module installation, insulation, scaffolding (CII, 2008). The metrics in the COAA benchmarking system are visually displayed in quartiles in reports and graphs. Many of these metrics relate to indirect and direct construction costs, mechanical and equipment costs, scaffolding work hours, the use of offsite modules, as well as various workforce metrics. COAA members input cost, schedule and safety data and engineering and construction information into the benchmarking system at two specific times in the project life cycle,

\section{Major Risks in SAGD projects}

What risk do you think are associated with a SAGD project?

The participants were asked about the major risks associated with SAGD projects. How they are different from other industrial projects. Most participants responded that SAGD projects are similar to other industrial projects. During the SAGD project execution most of the construction risks are similar to other industrial project and major risks identified from the interviews are listed below:

1. Quality of Reservoir.

2. Key project team members not qualified

3. Owner driven changes to project objectives or scope

4. Weather windows, bird nesting season and road bans

5. Owner personnel unfamiliar with Alberta conditions

6. Owner cash flow restrictions

7. Lack of sufficiently qualified resources

8. Changing regulatory requirements

9. Changing public opinion about oil sands related developments

10. Lack of pipeline capacity to export product

11. Poor understanding of site work that needs to be done early versus site work that should wait until sufficient backlog of material and drawings are available.

12. Inappropriate delegation of decision-making authority

13. Insufficient risk mitigation planning and acting 
14. Poor definition or understanding of project objectives and value trade-offs (cost schedule, operability). Behaviour tends to be schedule-driven in the absence of this.

15. Dysfunctional teams and partnerships

\section{Discussions of the finding}

It was revealed that most companies have experience of 7 SAGD related projects in the last 15 years. This shows that any information provided on SAGD projects by these respondents can be credible and reliable. On the definition of capacity of SAGD projects, most of the respondents suggested that is barrels/day while few recommended dollar value of project based upon the capacity, steam oil ratio, cold water equivalent steam capacity. The research recommends the barrels/day as the definition of capacity of SAGD projects. From the life cycle of SAGD projects are broken down in level 2 WBS and which different subcontractors can execute. It was discovered from the analysis that CPF is more expensive when compared to other breakdown structure. However, different companies are using different terminology to define the various life cycle phases of SAGD projects. Take for example, for cost and schedule breakdown for each phase, most respondents agreed that percentage varies according to the size and capacity of the project.

The research reviewed that Procurement/Cosntruction phase is $75 \%$ of the total project cost while other phase in total constiutues the $25 \%$ of the total cost of the project. On the schedule prospective, Procurement/Construction phase constitute the $55 \%$ of the total project duration. In the risk associated with the SAGD project execution, most of the construction risks are similar to other industrial project. That means irrespective of construction of projects all the risks are mostly the same. Although, the developments of capital projects in Alberta were compounded by extremes experienced related to such things as labour availability, harsh weather conditions, and remote project locations, amongst others. Perhaps this maybe indicative of the fact that due to geographic location, weather conditions and size of the projects, there is complexity associated with the delivery of construction projects in the oil and gas sector in Alberta.

\section{Conclusion}

This paper discussed the interview finding of characteristics of SAGD projects based on information from the respondents. It also discussed the definition of capacity of SAGD projects as barrels/day, main feature of SAGD projects, which consists of Central Processing Facility (CPF), well pads, source and disposal water wells, offside pipelines and utilities. The life cycle of SAGD projects were broken down in level 2 WBS. It presented the data analysis where Procurement/Cosntruction phase is $75 \%$ of the total project cost while other phase in total constiutues the $25 \%$ of the total cost of the project. On the schedule prospective, procurement/construction phase constitute the $55 \%$ of the total project duration. The paper also discussed the major risks associated with SAGD projects execution and found that they are similar to other project risks. It concludes that the results of the study will help in achieving a higher rate of productivity in the Alberta oil and gas industry. 


\section{Acknowledgements}

The authors would like to thank Natural Sciences and Engineering Research Council of Canada (NSERC), Construction Owners Association of Alberta (COAA), Construction Industry Institute (CII) and COAA contributing members for providing financial support, data and guidance.

\section{References}

Alnoor, A. H. (2010). Effective Project Management of Oil \& Gas Projects: A Model for Oil Sands' SAGD Plants. A Thesis Submitted to the Faculty of Graduate Studies in Partial Fulfilment of the Requirements for the Degree of Master of Science. Department of Civil Engineering, University of Calgary, Calgary, Canada.

Anderson, K., \& McAdam, R. (2004). A critique of benchmarking and performance measurement: Lead or Lag? Benchmarking: An International Journal, 11(5), 465-483. http://dx.doi.org/10.1108/14635770410557708

CAPP. (2014). Canada's oil, natural gas and oil sands - Overview and outlook.

Creswell, J. W. (2003). Research Design: Qualitative, quantitative and Mixed Method Approaches. Thousand Oaks, California: Sage Publication.

Deming, W. E. (1982). Quality, Productivity, and Competitive Position: Center for Advanced Engineering Study. Massachusetts Institute of Technology, Cambridge, MA.

Franceschini, F., Galetto, M., \& Cecconi, P. (2006). A worldwide analysis of ISO 9000 standard diffusion: considerations and future development. Benchmarking: An International Journal, 13(4), 523-541. http://dx.doi.org/10.1108/14635770610676326

Jergeas, G. (2008). Analysis of the Front-End loading of Alberta mega Oil Sands Projects. Project management Journal, 39(4), 95-104. http://dx.doi.org/10.1002/pmj.20080

Jergeas, G. F. (2009). Improving Construction Productivity on Alberta Oil and Gas Capital Projects. Report to Alberta Finance and Enterprise project report, Alberta.

Lincoln, Y. S., \& Guba, E. G. (2000). Paradigmatic Controversies, Contradictions, and Emerging Confluences. In N. K. Dezin \& Y. S. Lincoln (Eds.), Handbook of Qualitative Research (2nd ed., pp. 163-188). Thousand Oaks, CA: Sage Publications Ltd.

McAdam, R., \& McCreedy, S. (1999). A critical review of knowledge management models. The Learning Organization: An International Journal, 6(3), 91-101. http://dx.doi.org/10.1108/09696479910270416

Moriarty, J. P., \& Smallman, C. (2009). En route to a theory of benchmarking. Benchmarking: An International Journal, 16(4), 484-503. http://dx.doi.org/10.1108/14635770910972423

Walker, D. H. T. (1997). Choosing an Methodology. Journal of Construction Management and Economics, 15(2), 149. http://dx.doi.org/10.1080/01446199700000003

Xerox. (1979). Benchmarking. Xerox Corporation, internal publication, London. 


\section{Copyright Disclaimer}

2015, Vol. 3, No. 2

Copyright for this article is retained by the author(s), with first publication rights granted to the journal.

This is an open-access article distributed under the terms and conditions of the Creative Commons Attribution license (http://creativecommons.org/licenses/by/3.0/). 